\title{
Effect of Different Precursors in the Chemical Synthesis of ZnO Nanocrystals
}

\author{
Marivone Gusatti*, Gilvan Sérgio Barroso ${ }^{\mathrm{a}}$, Carlos Eduardo Maduro de Campos ${ }^{\mathrm{b}}$,
}

Daniel Aragão Ribeiro de Souza a, Jeane de Almeida do Rosário ${ }^{\text {a }}$ Raquel Bohn Lima a,

Camila Cardoso Milioli, Laura Abreu Silva, Humberto Gracher Riella, Nivaldo Cabral Kuhnen ${ }^{\text {a }}$

\author{
a Departamento de Engenharia Química e Engenharia de Alimentos, \\ Programa de Pós-Graduação em Engenharia Química, \\ Universidade Federal de Santa Catarina - UFSC, Campus Universitário, \\ CP 476, CEP 88040-900, Florianópolis, SC, Brazil \\ ${ }^{\mathrm{b}}$ Departamento de Física, Universidade Federal de Santa Catarina - UFSC, \\ Campus Universitário, CEP 88040-900, Florianópolis, SC, Brazil
}

Received: March 16, 2011; Revised: May 2, 2011

\begin{abstract}
This work evaluates the effect of $\mathrm{ZnCl}_{2}$ and $\mathrm{Zn}\left(\mathrm{NO}_{3}\right)_{2} \cdot 6 \mathrm{H}_{2} \mathrm{O}$ as precursors in the synthesis of $\mathrm{ZnO}$ nanocrystals. The materials were obtained at $90^{\circ} \mathrm{C}$ by a simple solochemical route. The resulting samples were characterized regarding phase composition, particle size and morphology, by means of XRD and TEM. The analysis have provided evidences that the material obtained applying $\mathrm{Zn}\left(\mathrm{NO}_{3}\right)_{2} \cdot 6 \mathrm{H}_{2} \mathrm{O}$ as precursor has hexagonal crystalline structure, typical of the $\mathrm{ZnO}$, and dimensions in the nanoscale. However, applying $\mathrm{ZnCl}_{2}$ as precursor results in a mixture of $\mathrm{ZnO}$ and $\mathrm{Zn}_{5}(\mathrm{OH})_{8} \mathrm{Cl}_{2} \cdot \mathrm{H}_{2} \mathrm{O}$ phases. For both precursors, the predominant morphology of the obtained $\mathrm{ZnO}$ nanocrystals was the rod-like structure.
\end{abstract}

Keywords: nanocrystalline materials, zinc oxide, solochemical method

\section{Introduction}

Nanotechnology has drawn the attention of researchers worldwide due to the many innovations revealed by reducing the size of the materials to the nanoscale. Such innovations include very peculiar properties, different even from the material itself on a larger scale. A material is considered nanometric when its structural components have at least one dimension in the nanometer scale.

Due to its extraordinary mechanical, electrical, magnetic, optical and chemical properties, zinc oxide is one of the most studied materials in nanotechnology. $\mathrm{ZnO}$ has hexagonal wurtzite structure, lattice parameters $\mathrm{a}=3.2539 \AA$ and $\mathrm{c}=5.2098 \AA$, and belongs to the space group $P 6_{3} m c^{1}$. This material stands out among the semiconductors due to its large band gap (3.37 eV) associated with a high exciton binding energy $(60 \mathrm{meV})^{2,3}$. Reducing the size of the $\mathrm{ZnO}$ to the nanoscale changes its properties significantly, since they are dependent on the size, orientation and morphology of the particles ${ }^{4}$. This material has many technological applications such as opto-electronic devices, catalysts, cosmetics, gas sensors, varistors and pigments ${ }^{5-8}$.

The synthesis of $\mathrm{ZnO}$ nanostructures may be accomplished by physical and chemical routes. However, chemical methods are

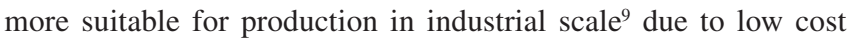
and efficiency in obtaining nanostructures with uniform size and morphology ${ }^{10}$. Among the chemical methods, the solochemical technique stands out for its simple, quick and inexpensive production of $\mathrm{ZnO}$ nanocrystals with high quality. Moreover, this method uses milder reaction conditions than those necessary to most of the chemical methods proposed in the literature ${ }^{11}$. This technique consists of the reaction between a heated alkaline solution and a precursor solution at room temperature. Furthermore, under controlled temperature, the decomposition of the reactants is initiated causing the immediate formation of $\mathrm{ZnO}$ nanocrystals ${ }^{12,13}$.
In this work, different materials were obtained by solochemical processing using $0.7 \mathrm{~mol} . \mathrm{L}^{-1}$ precursor solutions of zinc chloride $\left(\mathrm{ZnCl}_{2}\right)$ and zinc nitrate hexahydrate $\left(\mathrm{Zn}\left(\mathrm{NO}_{3}\right)_{2} \cdot 6 \mathrm{H}_{2} \mathrm{O}\right)$. The reactions with both precursors were performed at $90^{\circ} \mathrm{C}$. The samples were characterized by X-ray diffraction (XRD), Rietveld method and transmission electron microscopy (TEM).

\section{Experimental Procedure}

In this study, samples were prepared using two different 0.7 mol. $\mathrm{L}^{-1}$ precursor solutions $\left(\mathrm{Zn}\left(\mathrm{NO}_{3}\right)_{2} \cdot 6 \mathrm{H}_{2} \mathrm{O}\right.$ and $\left.\mathrm{ZnCl}_{2}\right)$ mixed with a 1.0 mol. $\mathrm{L}^{-1}$ sodium hydroxide $(\mathrm{NaOH})$ solution. These reagents were of analytical grade and were used without further purification.

The experimental arrangement and procedure for the production of samples by solochemical processing are simple and identical for both precursors. Were used basically a reactor, a separation funnel and a magnetic stirrer with temperature control. Equal volumes of each solution were prepared by dissolution of the reagents $\left(\mathrm{Zn}\left(\mathrm{NO}_{3}\right)_{2} \cdot 6 \mathrm{H}_{2} \mathrm{O}, \mathrm{ZnCl}_{2}\right.$ and $\left.\mathrm{NaOH}\right)$ in deionized water, at room temperature. Afterwards, the alkaline solution was placed inside the reactor and heated to $90{ }^{\circ} \mathrm{C}$ under constant stirring. At this temperature, the precursor solution $\left(\mathrm{Zn}\left(\mathrm{NO}_{3}\right)_{2} \cdot 6 \mathrm{H}_{2} \mathrm{O}\right.$ or $\left.\mathrm{ZnCl}_{2}\right)$ was slowly added into the reactor for 1 hour under vigorous stirring.

After the addition of the precursor solution, the suspension formed was kept for over two hours under vigorous stirring at $90{ }^{\circ} \mathrm{C}$. After this time, the reaction product was filtered, washed several times with deionized water, and dried in a vacuum oven at $65^{\circ} \mathrm{C}$ for a few hours.

The materials characterization was performed by X-ray diffraction, using a diffractometer PanAnalytical X'Pert PRO MultiPurpose with radiation $\mathrm{Cu} K \alpha(\lambda=1.5418 \AA)$ operating at $40 \mathrm{kV}$ and $30 \mathrm{~mA}$. The $2 \theta$ variation was employed with a 0.05 degrees step and a time step of 1 second. To estimate the average crystallite size, 
the XRD patterns were refined by Rietveld method with a modified pseudo-Voigt profile function by the Rietveld method using the GSAS program package ${ }^{14,15}$. Refinements were carried out with a starting model based on structural information provided by the ICSD ${ }^{16}$ database and on instrumental dispersion determined using an $\mathrm{Y}_{2} \mathrm{O}_{3}$ standard. The morphology and particle size of the obtained products were analyzed by transmission electron microscopy using a JEOL JEM 1011 microscope operating at $100 \mathrm{kV}$.

\section{Results and Discussion}

The crystalline structure of the sample formed at $90{ }^{\circ} \mathrm{C}$ by chemical reaction between $\mathrm{NaOH}$ and $\mathrm{Zn}\left(\mathrm{NO}_{3}\right)_{2} \cdot 6 \mathrm{H}_{2} \mathrm{O}$ was examined by XRD (Figure 1). In the same figure, the diffraction pattern of $\mathrm{ZnO}$, available at the ICSD database (Card No. 57 450), is shown for comparison. The diffractogram of the sample can be explained

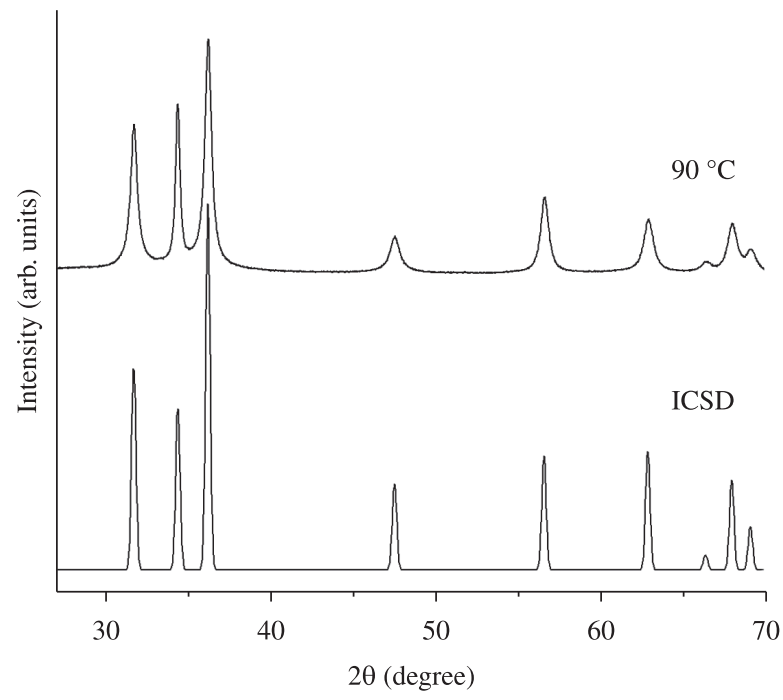

Figure 1. XRD pattern of the sample prepared at $90{ }^{\circ} \mathrm{C}$ with $\mathrm{Zn}\left(\mathrm{NO}_{3}\right)_{2} \cdot 6 \mathrm{H}_{2} \mathrm{O}$ by solochemical processing. The ICSD card No. 57450 is also shown for comparison.

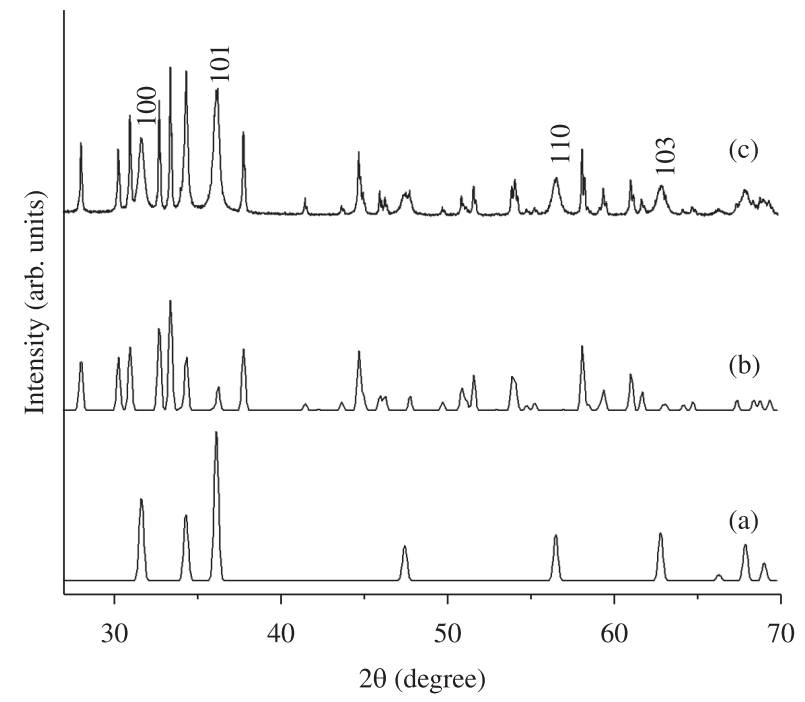

Figure 2. XRD patterns of a) $\mathrm{ZnO}$ (ICSD card No. 57450 ), b) $\mathrm{Zn}_{5}(\mathrm{OH})_{8} \mathrm{Cl}_{2}$. $\mathrm{H}_{2} \mathrm{O}$ (ICSD card No. 16973 ) and c) sample prepared at $90{ }^{\circ} \mathrm{C}$ with $\mathrm{ZnCl}_{2}$ by solochemical processing. only by the hexagonal wurtzite structure (space group $P 6_{3} m c$ and lattice parameters $\mathrm{a}=3.25 \AA$ and $\mathrm{c}=5.20 \AA$ ) of $\mathrm{ZnO}$ reported in the ICSD database. However, the diffraction peaks of the sample are considerably broader than those presented by the ICSD pattern. Such broadening is a typical feature of nanometer-scale materials. The absence of extra peaks, which could be related to impurities, indicates that the $\mathrm{ZnO}$ sample produced with $\mathrm{Zn}\left(\mathrm{NO}_{3}\right)_{2} \cdot 6 \mathrm{H}_{2} \mathrm{O}$ has high quality. Thus, the experimental diffraction pattern confirms that the proposed route, using $\mathrm{Zn}\left(\mathrm{NO}_{3}\right)_{2} \cdot 6 \mathrm{H}_{2} \mathrm{O}$ as precursor, is suitable for the production of $\mathrm{ZnO}$.

The XRD pattern of the sample obtained applying $\mathrm{Zn}\left(\mathrm{NO}_{3}\right)_{2} \cdot 6 \mathrm{H}_{2} \mathrm{O}$ as precursor was refined by Rietveld method. The anisotropic average
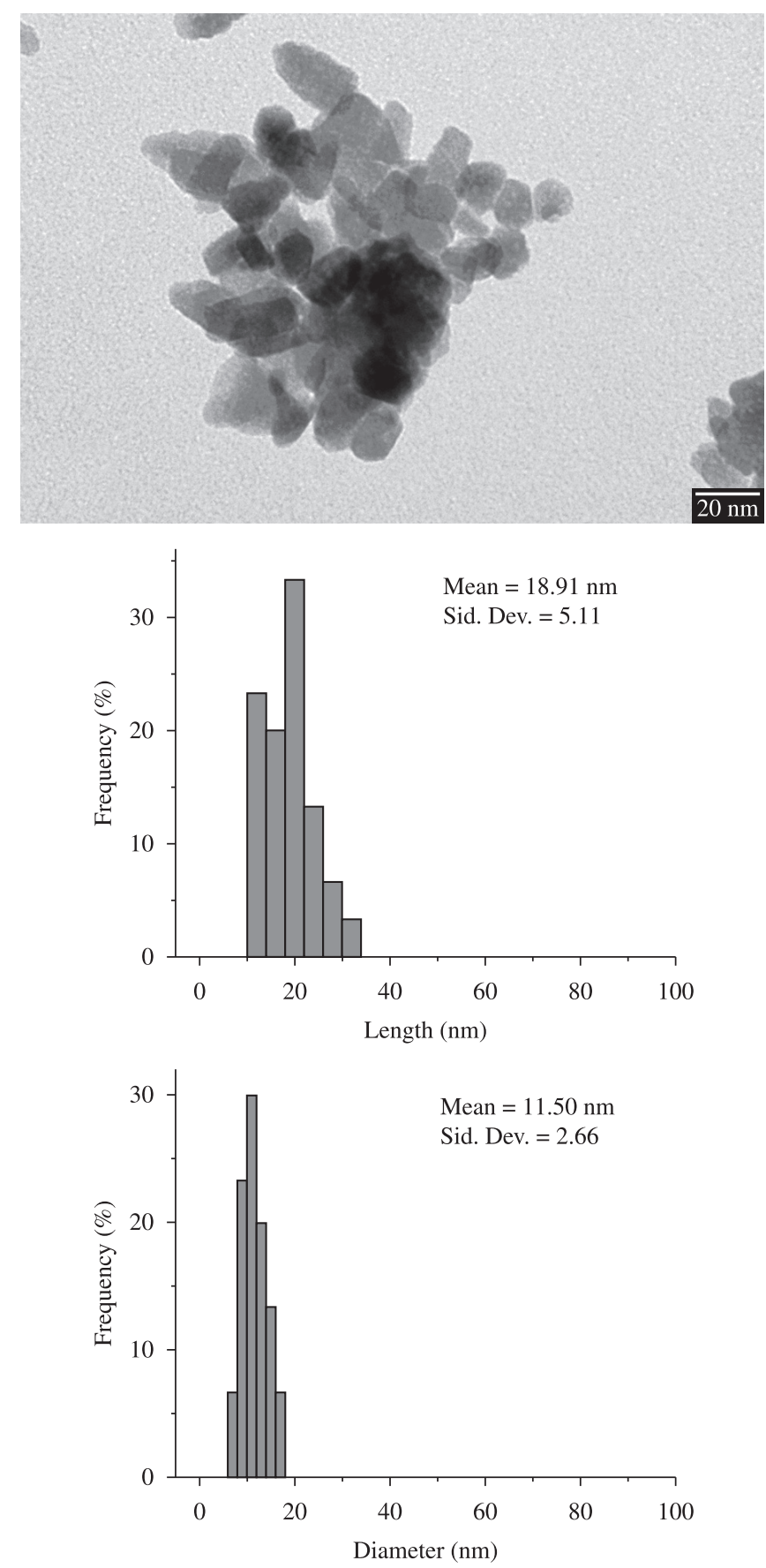

Figure 3. TEM results of the $\mathrm{ZnO}$ nanocrystals produced at $90{ }^{\circ} \mathrm{C}$ using $\mathrm{Zn}\left(\mathrm{NO}_{3}\right)_{2} \cdot 6 \mathrm{H}_{2} \mathrm{O}$. 


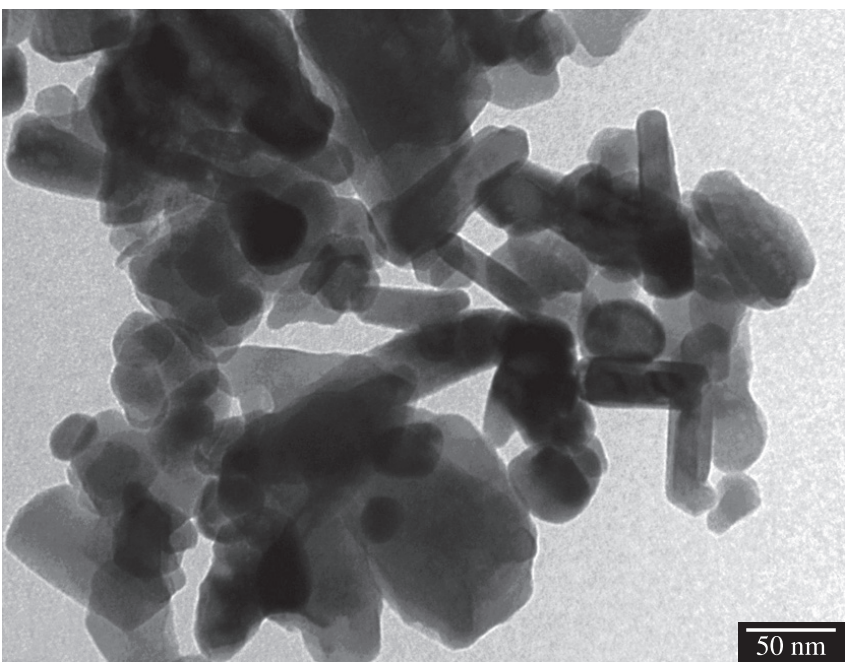

Figure 4. TEM image of the material produced at $90{ }^{\circ} \mathrm{C}$ using $\mathrm{ZnCl}_{2}$.

crystallite sizes for this sample were $20 \mathrm{~nm}$ (perpendicular) and $29 \mathrm{~nm}$ (parallel).

The crystalline structure of the sample formed at $90{ }^{\circ} \mathrm{C}$ by chemical reaction between $\mathrm{NaOH}$ and $\mathrm{ZnCl}_{2}$ was also analyzed by XRD (Figure 2). The diffractogram shows that the product formed exhibit the characteristic diffraction peaks of $\mathrm{ZnO}$ with hexagonal wurtzite structure (space group $\mathrm{Pb}_{3} m c$ ). These peaks are probably related to the crystalline planes (100), (101), (110) and (103) of $\mathrm{ZnO}$. However, most of the diffraction peaks do not match with the diffraction pattern of the $\mathrm{ZnO}$. The positions of these peaks coincide well with those of the hexagonal phase of the crystal $\mathrm{Zn}_{5}(\mathrm{OH})_{8} \mathrm{Cl}_{2} \cdot \mathrm{H}_{2} \mathrm{O}$ (space group $R-3 m H$, lattice parameters $\mathrm{a}=6.34 \AA$ and $\mathrm{c}=23.64 \AA$ ), reported in the ICSD card No. 16973 (Figure 2b).

According to previous studies ${ }^{17,18}$, depending on the concentration of the precursor solution, the nanostructures prepared by chemical or electrochemical methods may exhibit in their composition $\mathrm{ZnO}$ particles mixed with other phases such as $\mathrm{Zn}(\mathrm{OH})_{2}$ and $\mathrm{Zn}_{5}(\mathrm{OH})_{8} \mathrm{Cl}_{2} \cdot \mathrm{H}_{2} \mathrm{O}$. The presence of these phases in the final composition of the material indicates that the conversion of reactants into the desired $\mathrm{ZnO}$ product was not complete.

Studies indicate that the compound $\mathrm{Zn}_{5}(\mathrm{OH})_{8} \mathrm{Cl}_{2} \cdot \mathrm{H}_{2} \mathrm{O}$ is formed when the concentration of the $\mathrm{Zn}^{2+}$ ions is higher than $0.01 \mathrm{M}^{19}$, which is in agreement with the results obtained in this study, considering that $\mathrm{Zn}_{5}(\mathrm{OH})_{8} \mathrm{Cl}_{2} \cdot \mathrm{H}_{2} \mathrm{O}$ crystals were produced using a $0.7 \mathrm{M}$ solution of $\mathrm{ZnCl}_{2}$. Furthermore, the formation of this compound can be also caused by the low reaction temperature used in this preparation procedure. The literature shows that the $\mathrm{Zn}_{5}(\mathrm{OH})_{8} \mathrm{Cl}_{2} \cdot \mathrm{H}_{2} \mathrm{O}$ can be completely decomposed into $\mathrm{ZnO}$ upon calcination at $500{ }^{\circ} \mathrm{C}$ or higher ${ }^{4}$.

Transmission electron microscopy was used to examine the morphological characteristics of the product synthesized at $90{ }^{\circ} \mathrm{C}$ employing $\mathrm{Zn}\left(\mathrm{NO}_{3}\right)_{2} \cdot 6 \mathrm{H}_{2} \mathrm{O}$ as precursor (Figure 3). The image shows the presence of short nanoprisms and nanorods. These particles have an average length (which is equivalent to parallel crystallite size) of $18.91 \mathrm{~nm}$ and an average diameter (which is equivalent to perpendicular crystallite size) of $11.50 \mathrm{~nm}$.

TEM was also used to examine the size and morphology of the material synthesized at $90{ }^{\circ} \mathrm{C}$ employing $\mathrm{ZnCl}_{2}$ as precursor (Figure 4). The TEM image clearly shows the presence of nanorods, which is one of the $\mathrm{ZnO}$ typical morphologies. These nanorods have an average diameter of about $23 \mathrm{~nm}$.

\section{Conclusions}

In this work, $\mathrm{ZnO}$ nanocrystals were prepared by a cost-effective and simple solochemical technique using aqueous solutions of zinc nitrate hexahydrate and sodium hydroxide at $90^{\circ} \mathrm{C}$. The $\mathrm{ZnO}$ products formed by this method have high quality. The X-ray diffraction results confirmed the efficiency of the synthesis process, evidencing the production of single crystalline $\mathrm{ZnO}$ particles with hexagonal wurtzite structure. The average crystallite sizes obtained by Rietveld method for this sample were $20 \mathrm{~nm}$ (perpendicular) and $29 \mathrm{~nm}$ (parallel). The transmission electron microscopy showed that the particles have nanometric prism-like and rod-like morphologies.

The XRD results indicated that the use of $\mathrm{ZnCl}_{2}$ as precursor alters the composition of the final product, forming $\mathrm{ZnO}$ nanocrystals mixed with $\mathrm{Zn}_{5}(\mathrm{OH})_{8} \mathrm{Cl}_{2} \cdot \mathrm{H}_{2} \mathrm{O}$ crystals. The obtained $\mathrm{ZnO}$ nanostructures exhibited rod-like morphology and average diameter of approximately $23 \mathrm{~nm}$. Hence, XRD results indicate the lower efficiency of the proposed solochemical method in the synthesis of $\mathrm{ZnO}$ nanocrystals using high concentration of $\mathrm{ZnCl}_{2}$ precursor solution.

\section{Acknowledgements}

The authors would like to acknowledge the Central Laboratory of Electron Microscopy (LCME) and X-ray Diffraction Laboratory (LDRX) of the Federal University of Santa Catarna by TEM and XRD measurements, respectively.

\section{References}

1. Liu R, Vertegel AA, Bohannan EW, Sorenson TA and Switzer JA. Epitaxial electrodeposition of zinc oxide nanopillars on single-crystal gold. Chemistry of Materials. 2001; 13:508-512. doi:10.1021/cm0007631

2. Kubota J, Haga K, Kashiwaba Y, Watanabe H, Zhang BP and Segawa $\mathrm{Y}$. Characteristics of $\mathrm{ZnO}$ whiskers prepared from organic-zinc. Applied Surface Science. 2003; 216:431-435. doi:10.1016/ S0169-4332(03)00388-X

3. Fu Y-S, Du X-W, Sun J, Song Y-F and Liu J. Single-crystal ZnO cup based on hydrothermal decomposition route. Journal of Physical Chemistry. 2007; 111:3863-3867.

4. Duan J-X, Wang H and Huang X-T. Synthesis and characterization of $\mathrm{ZnO}$ ellipsoid-like nanostructures. Chinese Journal of Chemical Physics. 2007; 20:613-618. doi:10.1088/1674-0068/20/06/613-618

5. Liu Y, Zhou J, Larbot A and Persin M. Preparation and characterization of nano-zinc oxide. Journal of Materials Processing Technology. 2007; 189:379-383. doi:10.1016/j.jmatprotec.2007.02.007

6. Viswanatha R, Sapra S, Satpati B, Satyam PV, Dev BN and Sarma DD. Understanding the quantum size effects in $\mathrm{ZnO}$ nanocrystals. Journal of Materials Chemistry. 2004; 14:661-668. doi:10.1039/b310404d

7. Kanade KG, Kale BB, Aiyer RC and Das BK. Effect of solvents on the synthesis of nano-size zinc oxide and its properties. Materials Research Bulletin. 2006; 41:590-600. doi:10.1016/j.materresbull.2005.09.002

8. Duffy GM, Pillai SC and Mccormack DE. A novel processing route for the production of nanoparticulate zinc oxide using an isophthalate precursor. Smart Materials and Structures. 2007; 16:1379-1381. doi:10.1088/09641726/16/4/052

9. Wu C, Qiao X, Chen J, Wang H, Tan F and Li S. A novel chemical route to prepare $\mathrm{ZnO}$ nanoparticles. Materials Letters. 2006; 60:1828-1832. doi:10.1016/j.matlet.2005.12.046

10. $\mathrm{Hu} \mathrm{Y}$ and Chen HJ. Preparation and characterization of nanocrystalline $\mathrm{ZnO}$ particles from a hydrothermal process. Journal of Nanoparticle Research. 2008; 10:401-407. doi:10.1007/s11051-007-9264-0

11. Gusatti M, Rosario JA, Barroso GS, Campos CEM, Riella HG and Kuhnen NC. Synthesis of $\mathrm{ZnO}$ nanostructures in low reaction temperature. Chemical Engineering Transactions. 2009; 17:1017-1022. 
12. Vaezi MR and Sadrnezhaad SK. Nanopowder synthesis of zinc oxide via solochemical processing. Materials \& Design. 2007; 28:515-519. doi:10.1016/j.matdes.2005.08.016

13. Gusatti M, Rosário JA, Campos CEM, Kuhnen NC, Carvalho EU, Riella $\mathrm{HG}$ et al. Production and characterization of $\mathrm{ZnO}$ nanocrystals obtained by solochemical processing at different temperatures. Journal for Nanoscience and Nanotechnology. 2010; 10:4348-4351. PMid:21128423. doi:10.1166/jnn.2010.2198

14. Larson AC and Von Dreele RB. General Structure Analysis System (GSAS). Los Alamos: Los Alamos National Laboratory Report; 2000. (LAUR 86-748).

15. Toby BH. EXPGUI, a graphical user interface for GSAS. Journal of Applied Crystallography. 2001; 34:210-213. doi:10.1107/S0021889801002242
16. Inorganic Crystal Structure Database (ICSD). Karlsruhe, Germany: Gmelin-Institut für Anorganische Chemie and Fachinformationszentrum FIZ; 2007.

17. Chatterjee AP, Mitra P and Mukhopadhyay AK. Chemically deposited zinc oxide thin film gas sensor. Journal of Materials Science. 1999; 34:4225-4231. doi:10.1023/A:1004694501646

18. Rakhshani AE. Boron-doped $\mathrm{ZnO}$ films grown by successive chemical solution deposition. Journal of Physics D: Applied Physics. 2008; 41:1-6. doi:10.1088/0022-3727/41/1/015305

19. Pradhan D and Leung KT. Controlled growth of two-dimensional and one-dimensional $\mathrm{ZnO}$ nanostructures on indium tin oxide coated glass by direct electrodeposition. Langmuir. 2008; 24:9707-9716. PMid:18652422. doi:10.1021/la8008943 